\title{
Physiological mechanisms of dehydration tolerance contribute to the invasion potential of Ceratitis capitata (Wiedemann) (Diptera: Tephritidae) relative to its less widely distributed congeners
}

\author{
Christopher W. Weldon', Leigh Boardman ${ }^{2,3}$, Danica Marlin ${ }^{1,4}$ and John S. Terblanche $2^{2^{*}}$
}

\begin{abstract}
Background: The Mediterranean fruit fly, Ceratitis capitata (Wiedemann) (Diptera: Tephritidae) is a highly invasive species now with an almost cosmopolitan distribution. Two other damaging, polyphagous and closely-related species, the marula fruit fly, Ceratitis cosyra (Walker), and the Natal fly, Ceratitis rosa Karsch, are not established outside of sub-Saharan Africa. In this study, adult water balance traits and nutritional body composition were measured in all three species at different temperatures and levels of relative humidity to determine whether tolerance of water stress may partially explain their distribution.

Results: Adult C. capitata exhibited higher desiccation resistance than C. rosa but not C. cosyra. Desiccation resistance of $C$. capitata was associated with lower rates of water loss under hot and dry conditions, higher dehydration tolerance, and higher lipid reserves that were catabolised during water stress. In comparison with C. capitata, C. cosyra and C. rosa lost water at significantly higher rates under hot, dry conditions, and did not catabolise lipids or other sources of metabolic water during water stress.

Conclusions: These results suggest that adult physiological traits permitting higher tolerance of water stress play a role in the success of $C$. capitata, particularly relative to C. rosa. The distribution of C. cosyra is likely determined by the interaction of temperature with water stress, as well as the availability of suitable hosts for larval development.
\end{abstract}

Keywords: Desiccation resistance, Water loss, Dehydration tolerance, Starvation, Body composition

\section{Background}

Environmental stress resistance, and a species ability to adapt to novel or variable environments, is of central interest in biology as it contributes to niche partitioning and biogeographic patterns. Environmental adaptations have particular importance for invasion biology because the ability of invasive species to survive variable environmental conditions has been suggested as a key trait that contributes to their dispersal and potential to invade

\footnotetext{
* Correspondence: jst@sun.ac.za

${ }^{2}$ Centre for Invasion Biology, Department of Conservation Ecology and Entomology, Stellenbosch University, Private Bag X1, Matieland 7602, South Africa

Full list of author information is available at the end of the article
}

new habitats [1]. Invasive species are introduced species that cause negative impacts on the environment, human activities, or human health [1]; as such they are regarded as major global threats and their management is an international research priority. Invasive insects pose a particular threat because they can be highly mobile and have high reproductive rates [2]. As climate change increases global temperatures, the threat of invasive insect species will increase as tropical and subtropical insects expand their range into temperate areas [3]. In this context, the ability of insects to withstand desiccation is likely to contribute to their invasive potential because, as they move away from the wetter tropical and subtropical 
regions, they will be exposed to reduced rainfall and increasingly dry environments [3].

The genus Ceratitis (Diptera: Tephritidae) includes true fruit flies where females oviposit and larvae develop in ripening fruit. For this reason, some members of the genus, particularly those with wide host ranges, are notorious pests of commercial fruit production. Most Ceratitis species have an Afrotropical distribution [4], but those that are pests can also be highly invasive. The Mediterranean fruit fly, Ceratitis capitata (Wiedemann) is a case in point $[5,6]$. Historical records of spread, and analyses of biochemical and molecular markers (e.g., see $[7,8])$ suggest that the species originated in central eastern Africa. In association with the growth and development of the international fresh fruit trade $[5,6], C$. capitata has been introduced to, established successfully in, and expanded its range throughout many tropical, subtropical, and mild temperate habitats of the world [9-11]. The current, almost cosmopolitan distribution in suitable climates (excluding only central and eastern Asia; [12]) and highly polyphagous use of fruit hosts [reared from over 150 plant species in Africa alone; [13] has led to this species being considered the most economically damaging pest of horticulture in the world because of direct crop losses, pre- and postharvest control costs, and limited access or loss of access to fly-free export markets (e.g., see [14]). In contrast, two other damaging, polyphagous fruit flies from the same genus, the marula fruit fly, Ceratitis cosyra (Walker), and the Natal fly, Ceratitis rosa Karsch, have not become established outside of sub-Saharan Africa. Ceratitis cosyra has a much smaller host range than C. capitata (mostly recorded from the fruit of the indigenous marula, Sclerocarya birrea (A. Rich.) Hochst., or mango, Mangifera indica L., as well as other Anacardiaceae and Annonaceae), but its distribution stretches across central and eastern Africa [15]. Ceratitis rosa has a similar host range (in terms of species used and breadth of species) to C. capitata, but it is found only on the eastern side of Africa from Kenya, south in to South Africa, as well as some Indian Ocean islands where it has been introduced [15].

The successful invasion of $C$. capitata has been attributed to a range of factors. Ceratitis capitata is generally regarded as an $r$-selected species with life history traits that favour colonisation, such as small size, early reproduction, high growth rates, and efficient dispersal. It does not, however, have high competitive abilities, being displaced to ecological refuges where bioclimatic conditions do not favour competitively dominant species [16]. Field [17] and laboratory data [18-21] suggest that $C$. capitata can tolerate a wide range of temperatures, and that they outperform C. rosa at high temperatures in terms of adult critical thermal maximum and survival under semi-field conditions. Tolerance of water loss by C. capitata, or other Ceratitis species, has not been clearly established, but Duyck P-F, David P and Quilici S [17] provide data that indicate that $C$. capitata pupae are resistant to desiccation although intolerant of flooding. This differed from pupae of C. rosa, which were intolerant of desiccation but were unaffected by immersion in water for at least one hour. Data on the thermal limits or desiccation resistance of any life stage of C. cosyra are yet to be published, so the role of abiotic variables in determining their distribution is unclear.

There are only three possible, non-exclusive mechanisms for increased desiccation resistance at the organismal level: (1) increase water storage, (2) restrict water loss, or (3) increase tolerance to water loss [22]. These physiological mechanisms have all been reported in desiccation resistant species and populations, and have emerged in laboratory selection experiments. For example, different desiccation resistant lines of Drosophila melanogaster Meigen have reduced water permeability of the cuticle as a consequence of altered lipid composition, increased hemolymph volume, higher extracellular carbohydrate storage that increases hemolymph osmolality [23], and elevated tolerance to water loss and lipid storage [24]. Water content and dehydration tolerance are key to desiccation resistance of southern African keratin beetles [25, 26]. Desiccation resistance can also be achieved through reduced rates of respiration; Drosophila species from dry environments are less active, have lower metabolic rates, and exhibit cyclic $\mathrm{CO}_{2}$ emission patterns that may reduce water loss caused by transpiration [27]. In adult tephritid flies, improvement in desiccation resistance has been associated with increased body size $[28,29]$, which is associated with higher water content [30]. There is also evidence that some populations of the Queensland fruit fly, Bactrocera tryoni (Froggatt), tolerate higher levels of water loss than others before death [30], although the molecular basis for this observation remains unknown.

This study determined the desiccation resistance of the adults of three tephritid fly species, $C$. capitata, $C$. cosyra and C. rosa, with the particular aim of establishing whether tolerance of water stress may contribute to the invasive success of $C$. capitata. Potential mechanisms underpinning desiccation resistance in the tested species were also investigated. To do so, desiccation resistance of each species (scored as survival) was assessed at four different levels of relative humidity $(0,33,75$ and $100 \%$ ) at both 25 and $30^{\circ} \mathrm{C}$. A temperature of $25^{\circ} \mathrm{C}$ is optimal for many life history traits in C. capitata and $C$. rosa, whereas long-term exposure to $30{ }^{\circ} \mathrm{C}$ impairs key fitness traits in both species [18]. Water content prior to the survival assay, water loss rates under the imposed conditions, water remaining at death after the assay 
(dehydration tolerance), and body composition prior to and after dehydration ( $0 \%$ relative humidity) or starvation (100\% relative humidity) were also measured to identify whether they reflected patterns of desiccation resistance. It was predicted that desiccation resistance of C. capitata would be higher than in other species, and this would result from either higher body water content, lower water loss rates, or higher tolerance to loss of water.

\section{Results}

\section{Initial condition}

Body mass of the three Ceratitis species was not significantly different from each other (Table 1). The range of body mass for C. capitata was $6.5-11.6 \mathrm{mg}$, and that for C. cosyra and C. rosa was $6.5-12.7 \mathrm{mg}$ and 5.4-13.2 $\mathrm{mg}$, respectively. In all species, females were significantly heavier than males (Fig. 1a). Body mass significantly predicted water content in all species (Table 1), with water content being higher in heavier flies (Additional file 1: Table S1). Mass-adjusted water content was significantly affected by species, sex, and the interaction of species and sex (Table 1). In C. capitata and C. cosyra, females had a higher water content than males, but the water content of females and males was similar in C. rosa (Fig. 1b).

\section{Desiccation resistance and dehydration tolerance}

Survival of flies during desiccation resistance assays was significantly affected by the main effects of species, sex, temperature, relative humidity and initial mass (Additional file 2: Table S2). Overall, C. capitata and $C$. cosyra survived significantly longer during

Table 1 General linear model for the effect of species and sex on body mass and body water of three Ceratitis species

\begin{tabular}{lllll}
\hline Dependent variable & SS & df & $F$ & $P$ \\
\hline $\begin{array}{lllll}\text { Body mass (mg) } \\
\text { Intercept }\end{array}$ & 1739.11 & 1 & 913.320 & $<0.001$ \\
Species & 11.54 & 2 & 3.031 & 0.052 \\
Sex & 27.39 & 1 & 14.384 & $<0.001$ \\
Species $\times$ Sex & 9.68 & 2 & 2.541 & 0.083 \\
Residuals & 217.07 & 114 & & \\
Body water (mg) & & & & \\
Intercept & 1.118 & 1 & 11.516 & $<0.001$ \\
Species & 1.525 & 2 & 7.858 & $<\mathbf{0 . 0 0 1}$ \\
Sex & 0.634 & 1 & 6.531 & $\mathbf{0 . 0 1 2}$ \\
Body mass & 79.312 & 1 & 817.171 & $<\mathbf{0 . 0 0 1}$ \\
Species $\times$ Sex & 0.724 & 2 & 3.731 & $\mathbf{0 . 0 2 7}$ \\
Residuals & 10.967 & 113 & & \\
\hline
\end{tabular}

Body mass was included as a covariate in the model for body water. Significant effects $(P<0.05)$ are indicated by bold type

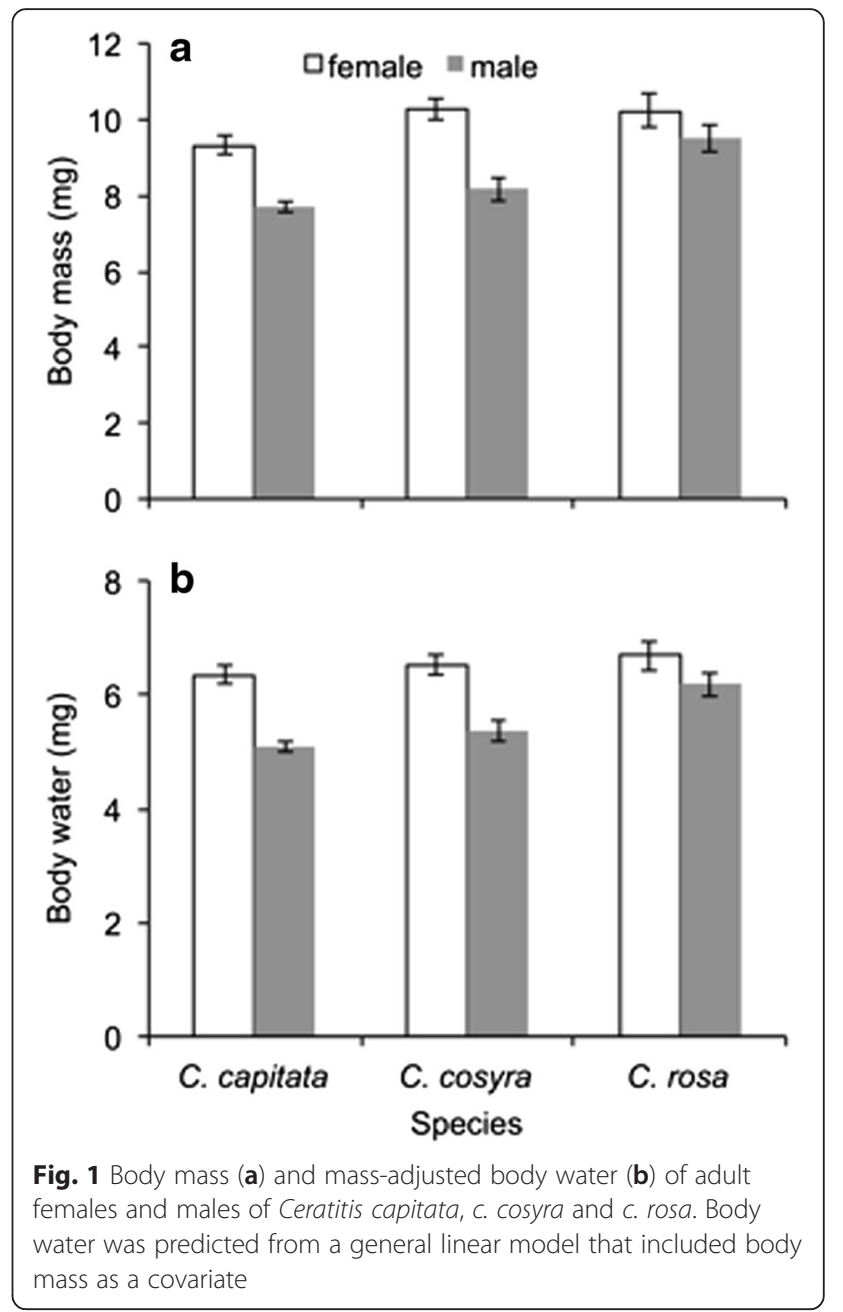

survival assays than C. rosa. However, complex significant interactions between species, sex, temperature and relative humidity were also found in the minimal adequate parametric survival model (Additional file 2: Table S2). For this reason, separate survival analyses were conducted for each species to explore the variation caused by the measured explanatory variables.

Survival time of C. capitata was significantly affected by the main effects of sex, temperature, relative humidity and initial mass (Table 2). Males survived longer than females, survival was shorter at $30{ }^{\circ} \mathrm{C}$ relative to $25{ }^{\circ} \mathrm{C}$, and survival time improved with increasing relative humidity (Fig. 2a), while accounting for increased survival in individuals with higher initial mass (coefficient estimate $=0.306$, s.e. $=0.089, t=3.427, p<0.001)$.

Within C. cosyra, the main effects of sex, temperature, relative humidity and initial mass were also significant predictors of survival, as well as the interaction of temperature and relative humidity (Table 2). When accounting for increased survival time as initial mass increased (coefficient estimate $=0.490$, s.e. $=0.056, t=8.820$, 
Table 2 Analysis of deviance table for the final fitted parametric survival model that describes desiccation resistance of three Ceratitis species with respect to sex, temperature (Temp) and relative humidity $(\mathrm{RH})$

\begin{tabular}{|c|c|c|c|}
\hline Predictor & $x^{2}$ & $d f$ & P \\
\hline \multicolumn{4}{|l|}{ C. capitata } \\
\hline Sex & 9.091 & 1 & 0.003 \\
\hline Temp & 57.463 & 1 & $<0.001$ \\
\hline $\mathrm{RH}$ & 57.639 & 3 & $<0.001$ \\
\hline Initial mass & 16.668 & 1 & $<0.001$ \\
\hline Sex $\times$ Temp & 2.969 & 1 & 0.085 \\
\hline \multicolumn{4}{|l|}{ C. cosyra } \\
\hline Sex & 7.250 & 1 & 0.007 \\
\hline Temp & 38.796 & 1 & $<0.001$ \\
\hline $\mathrm{RH}$ & 26.596 & 3 & $<0.001$ \\
\hline Initial mass & 31.884 & 1 & $<0.001$ \\
\hline Temp $\times$ RH & 18.694 & 3 & $<0.001$ \\
\hline \multicolumn{4}{|l|}{ C. rosa } \\
\hline Sex & 0.002 & 1 & 0.965 \\
\hline Temp & 1.852 & 1 & 0.174 \\
\hline $\mathrm{RH}$ & 51.066 & 3 & $<0.001$ \\
\hline Initial mass & 15.480 & 1 & $<0.001$ \\
\hline Sex $\times$ Temp & 3.724 & 1 & 0.054 \\
\hline Sex $\times R H$ & 5.126 & 3 & 0.163 \\
\hline Temp $\times R H$ & 4.847 & 3 & 0.183 \\
\hline Sex $\times$ Temp $\times R H$ & 17.247 & 3 & $<0.001$ \\
\hline
\end{tabular}

Initial body mass was included as a covariate in the model. Data were fitted to a Weibull hazard function. The analysis of deviance table was constructed using Type III likelihood ratio tests. Significant effects $(P<0.05)$ are indicated by bold type

$p<0.001$ ), female C. cosyra typically survived longer than males (Fig. 2b). When held at $25^{\circ} \mathrm{C}, \mathrm{C}$. cosyra survived for approximately $50 \mathrm{~h}$ when held at 0 or $33 \%$ relative humidity, but survived for approximately $70 \mathrm{~h}$ when relative humidity was higher. When held at $30^{\circ} \mathrm{C}$, survival time of C. cosyra was approximately $12 \mathrm{~h}$ shorter than at $25{ }^{\circ} \mathrm{C}$, except at $33 \%$ relative humidity (Fig. 2b).

Survival time of C. rosa was significantly affected by only the main effects of relative humidity and initial mass (Table 2). Again, survival was significantly improved by higher initial mass (coefficient estimate $=$ 0.433 , s.e. $=0.056, t=7.745, p<0.001)$. Survival generally increases with increasing relative humidity, but there was a significant interaction of sex and temperature with relative humidity (Table 2). The shortest survival time of C. rosa females and males was at $0 \%$ relative humidity, but was particularly low among males at $30{ }^{\circ} \mathrm{C}$ where mean survival was only $27 \mathrm{~h}$ (Fig. 2c). Regardless of temperature, female $C$. rosa survival at $0 \%$ relative humidity was similar, at approximately $39 \mathrm{~h}$. This contrasts
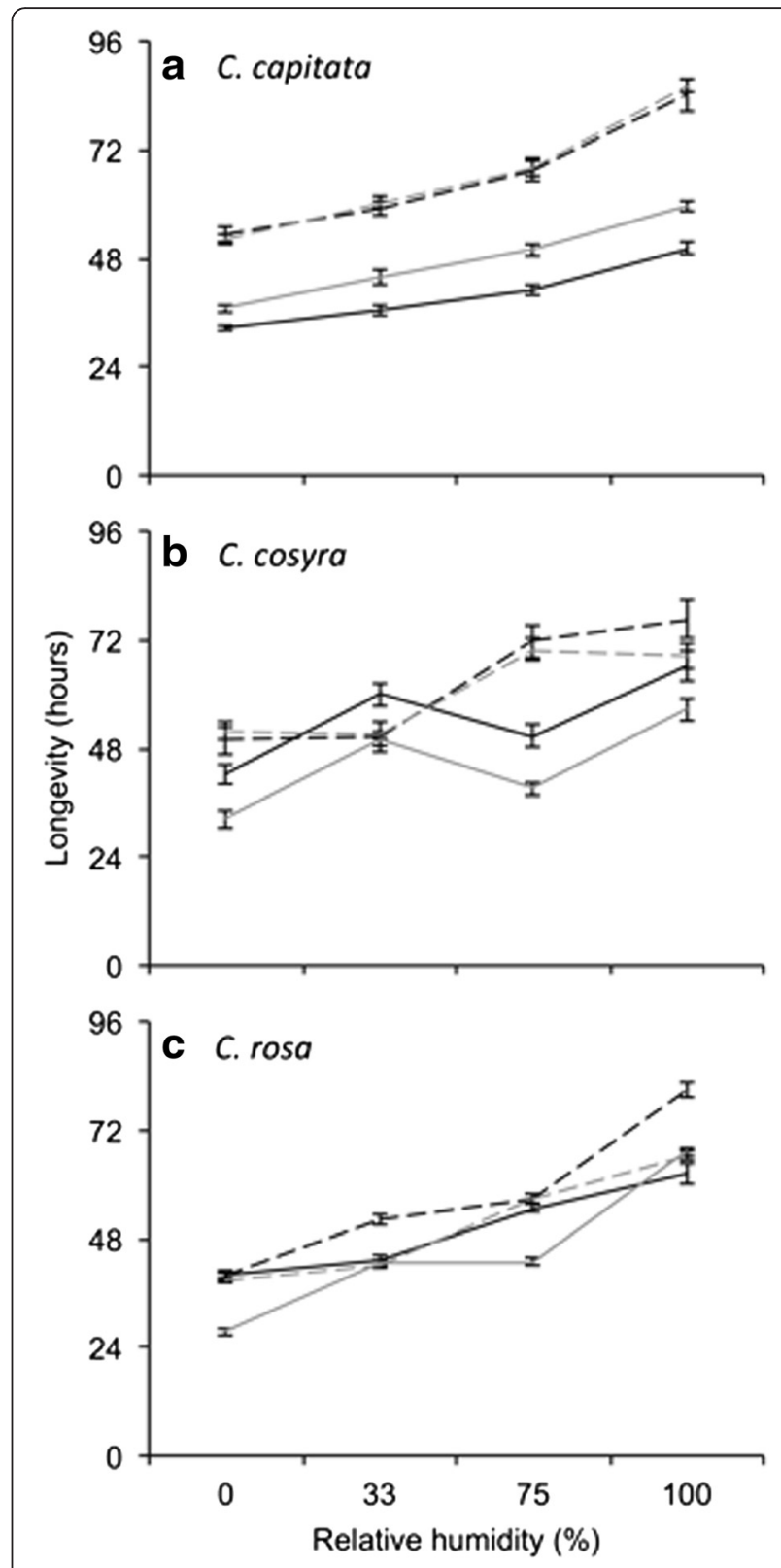

Fig. 2 Longevity of Ceratitis capitata (a), C. cosyra (b) and C. rosa (c) during an assay where individual females and males were starved at different temperatures and levels of relative humidity. Longevity was predicted from a parametric survival regression that included initial body mass as a covariate. Line colour represents the sexes: black $=$ female, grey $=$ male. Line style represents temperature: dashed $=25^{\circ} \mathrm{C}$, solid $=30^{\circ} \mathrm{C}$

with female survival at $100 \%$ relative humidity, where females held at $25{ }^{\circ} \mathrm{C}$ survived $18 \mathrm{~h}$ longer than those held at $30{ }^{\circ} \mathrm{C}$.

Watercontent at death of flies subjected to the desiccation resistance assay, an indicator of dehydration tolerance, was significantly predicted by estimated body water (Additional file 3: Table S3), with water at 
death positively associated with increasing estimated body water (coefficient estimate $=0.429$, s.e. $=0.036, t=$ $12.012, p<0.001)$. When taking this covariate into account, there was a significant four-way interaction effect of species, sex, temperature and relative humidity on water at death (Additional file 3: Table S3). In separate analyses for each species (Table 3), water remaining at death of flies was also significantly positively associated with estimated body water (C. capitata: coefficient

Table 3 Effects of sex, temperature (Temp) and relative humidity $(\mathrm{RH})$ on the water at death ( dehydration tolerance) of three Ceratitis species estimated using general linear models

\begin{tabular}{|c|c|c|c|c|}
\hline Dependent variable & SS & $\mathrm{df}$ & $\mathrm{F}$ & P \\
\hline \multicolumn{5}{|l|}{ C. capitata } \\
\hline Intercept & 1.948 & 1 & 5.740 & 0.018 \\
\hline Sex & 1.859 & 1 & 5.478 & 0.021 \\
\hline Temp & 0.177 & 1 & 0.521 & 0.471 \\
\hline $\mathrm{RH}$ & 1.974 & 3 & 1.939 & 0.126 \\
\hline Estimated body water & 3.985 & 1 & 11.742 & $<0.001$ \\
\hline Sex $\times$ Temp & 0.002 & 1 & 0.007 & 0.935 \\
\hline Sex $\times R H$ & 2.256 & 3 & 2.216 & 0.089 \\
\hline Temp $\times \mathrm{RH}$ & 0.977 & 3 & 0.959 & 0.414 \\
\hline Sex $\times$ Temp $\times R H$ & 3.657 & 3 & 3.592 & 0.015 \\
\hline Residuals & 48.534 & 143 & & \\
\hline \multicolumn{5}{|l|}{ C. cosyra } \\
\hline Intercept & 0.863 & 1 & 3.842 & 0.052 \\
\hline Sex & 0.550 & 1 & 2.447 & 0.120 \\
\hline Temp & 0.039 & 1 & 0.172 & 0.679 \\
\hline $\mathrm{RH}$ & 3.624 & 3 & 5.376 & 0.002 \\
\hline Estimated body water & 18.392 & 1 & 81.849 & $<0.001$ \\
\hline Sex $\times$ Temp & 0.855 & 1 & 3.807 & 0.053 \\
\hline Sex $\times R H$ & 2.446 & 3 & 3.628 & 0.015 \\
\hline Temp $\times \mathrm{RH}$ & 4.753 & 3 & 7.051 & $<0.001$ \\
\hline Residuals & 32.583 & 145 & & \\
\hline \multicolumn{5}{|l|}{ C. rosa } \\
\hline Intercept & 0.649 & 1 & 1.164 & 0.282 \\
\hline Sex & 1.622 & 1 & 2.909 & 0.090 \\
\hline Temp & 0.108 & 1 & 0.193 & 0.661 \\
\hline $\mathrm{RH}$ & 6.446 & 3 & 3.855 & 0.011 \\
\hline Estimated body water & 33.444 & 1 & 59.991 & $<0.001$ \\
\hline Sex $\times$ Temp & 0.346 & 1 & 0.621 & 0.432 \\
\hline Sex $\times R H$ & 0.463 & 3 & 0.277 & 0.842 \\
\hline Temp $\times \mathrm{RH}$ & 10.212 & 3 & 6.106 & $<0.001$ \\
\hline Sex $\times$ Temp $\times$ RH & 3.476 & 3 & 2.079 & 0.106 \\
\hline Residuals & 79.720 & 143 & & \\
\hline
\end{tabular}

Estimated body water (determined from initial body mass using the equations in Additional file 1: Table S1) was included as a covariate. Significant effects $(P<0.05)$ are indicated by bold type estimate $=0.306$, s.e. $=0.089, \mathrm{t}=3.427, \mathrm{p}<0.001 ; C$. cosyra: coefficient estimate $=0.490$, s.e. $=0.056, t=$ $8.820, p<0.001 ; C$. rosa: coefficient estimate $=0.433$, s.e. $=0.056, t=7.745, p<0.001)$. Within $C$. capitata, water at death was significantly affected by the main effect of sex, but also the three-way interaction of sex, temperature and relative humidity (Table 3 ). Overall, female C. capitata contained more water at death (i.e., were less dehydration tolerant) than males (Fig. 3a). When held at $30^{\circ} \mathrm{C}$, female $C$. capitata contained more water at death than those held at $25{ }^{\circ} \mathrm{C}$. However, in male C. capitata, there was no consistent effect of temperature on water at death at different levels of relative humidity. Water at death of C. cosyra was significantly affected by the main effect of relative humidity, and the interactions of sex and relative humidity, and temperature and relative humidity (Table 3). Female $C$. cosyra were less dehydration tolerant than males in unsaturated air, but at $100 \%$ relative humidity, water at death in males sharply increased (Fig. 3b). Water at death in $C$. cosyra stressed at $25{ }^{\circ} \mathrm{C}$ increased more gradually with increasing relative humidity than those stressed at $30{ }^{\circ} \mathrm{C}$ (Fig. 3b). Water at death in C. rosa was also significantly affected by the main effect of relative humidity, and the interaction of temperature and relative humidity (Table 3 ). In C. rosa, water at death increased significantly with increasing relative humidity, but there was a sharp increase in water at death from 33 to 75 and $100 \%$ relative humidity when flies were held at $30{ }^{\circ} \mathrm{C}$ (Fig. 3c). Sex of stressed flies did not significantly affect dehydration tolerance of $C$. rosa (Table 3).

\section{Water loss rate}

Water loss over a period of $24 \mathrm{~h}$ was affected by the four-way interaction of species, sex, temperature and relative humidity, and by initial mass (Additional file 4: Table S4). Overall, C. rosa suffered significantly higher rates of water loss than C. capitata and C. cosyra, principally driven by very high rates of water loss when held at $30{ }^{\circ} \mathrm{C}$ and $0 \%$ relative humidity (Fig. 4). When analysed separately, water loss rates of all three Ceratitis species were significantly affected by the main effects of temperature and relative humidity, and the interaction thereof (Table 4). For all three species, water loss rate increased with temperature, and declined as relative humidity increased (Fig. 4). However, the form of these responses differed among the species. When held at $25^{\circ} \mathrm{C}$, water loss by $C$. capitata declined significantly from low levels at $0 \%$ relative humidity to $0.45 \mathrm{mg} /$ day at $100 \%$ relative humidity (Fig. 4a). Water loss by C. capitata held at $30{ }^{\circ} \mathrm{C}$ did not follow a distinct decline with increasing relative humidity, instead fluctuating between 1.23 and $2.06 \mathrm{mg} /$ day across the tested range of relative humidity. In $C$. cosyra and $C$. rosa, water loss rate declined as 


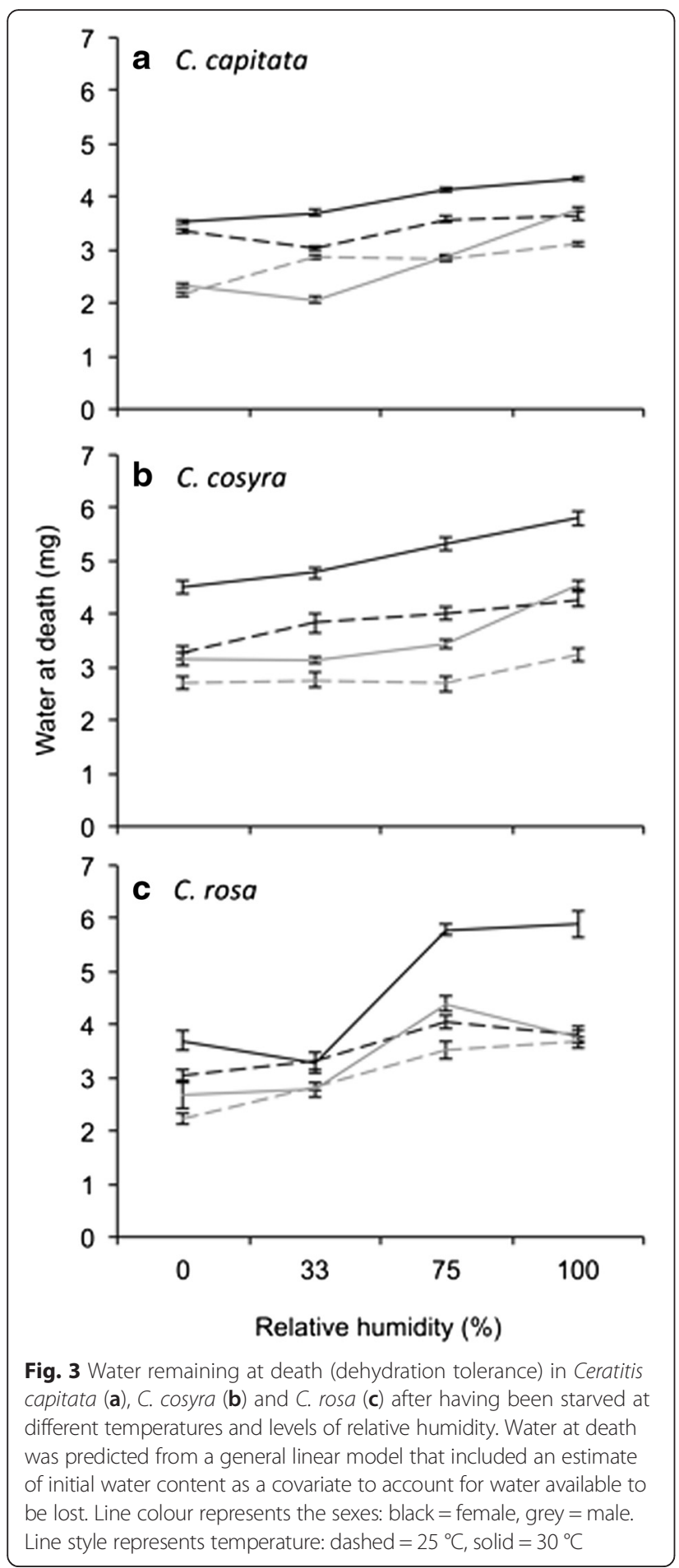

relative humidity increased, to the extent that both species gained water in saturated air (Fig. 4b, c). Water loss rate in C. cosyra and C. rosa was particularly pronounced at $30{ }^{\circ} \mathrm{C}$ and $0 \%$ relative humidity, being at least double, but up to four times greater, than water loss rate at $25^{\circ} \mathrm{C}$.

Water loss rate of $C$. cosyra and C. rosa was also affected by the significant interaction of sex with

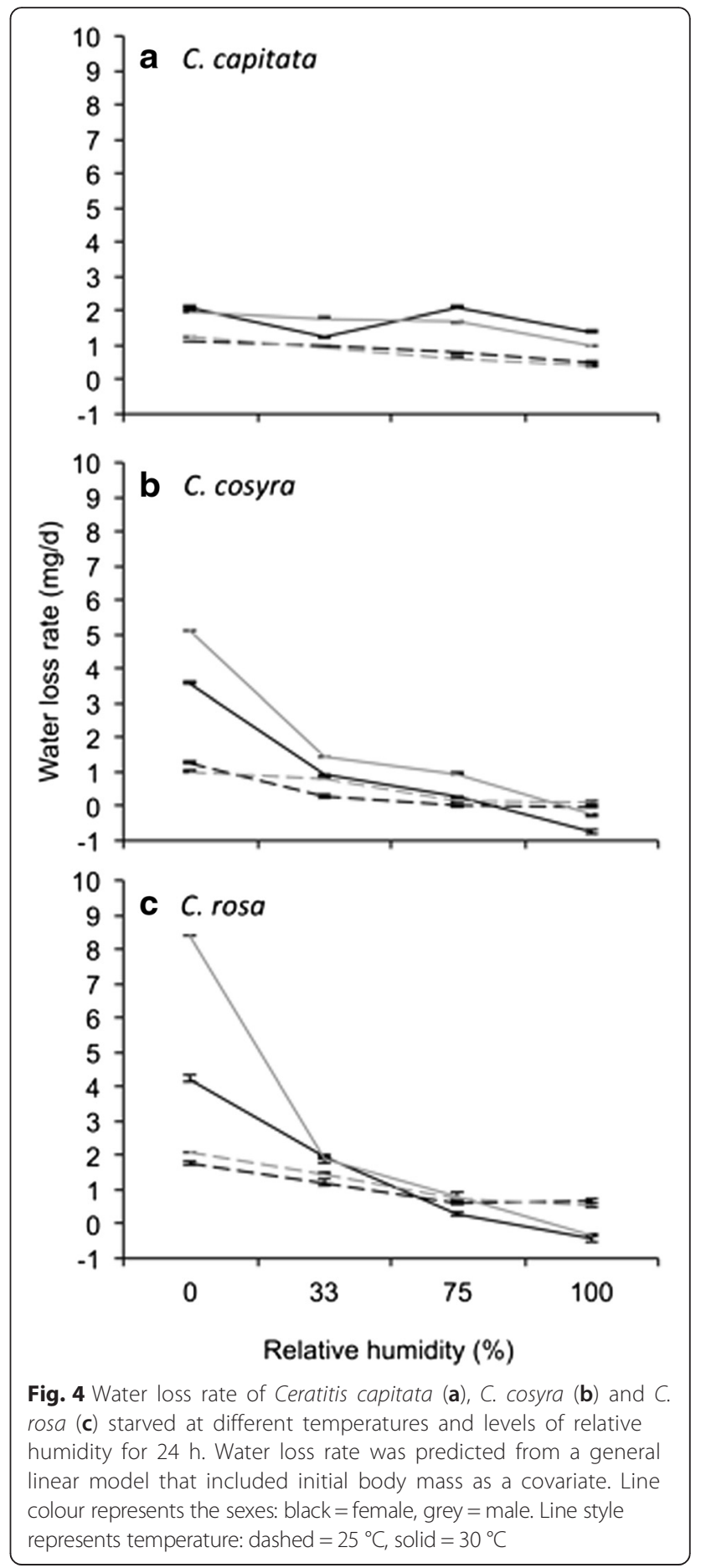

temperature. In both cases, males held at $30{ }^{\circ} \mathrm{C}$ had higher rates of water loss than females, but this difference was not evident at $25{ }^{\circ} \mathrm{C}$ (Fig. 4b, c). In C. rosa, there was an additional significant interaction of sex, temperature and relative humidity, which reflected a pronounced difference in water loss rate between females and males at $30{ }^{\circ} \mathrm{C}$ and $0 \%$ relative humidity, with males losing water at a rate twice that of females 
Table 4 Effects of sex, temperature (Temp) and relative humidity $(\mathrm{RH})$ on the water loss rate (expressed per day) of three Ceratitis species estimated using general linear models

\begin{tabular}{|c|c|c|c|c|}
\hline Dependent variable & SS & $d f$ & $\mathrm{~F}$ & $P$ \\
\hline \multicolumn{5}{|l|}{ C. capitata } \\
\hline Intercept & 0.102 & 1 & 0.594 & 0.443 \\
\hline Sex & 0.195 & 1 & 1.137 & 0.289 \\
\hline Temp & 3.766 & 1 & 21.933 & $<0.001$ \\
\hline $\mathrm{RH}$ & 1.819 & 3 & 3.532 & 0.018 \\
\hline Initial mass & 0.378 & 1 & 2.203 & 0.141 \\
\hline Sex $\times$ Temp & 0.066 & 1 & 0.382 & 0.538 \\
\hline Sex $\times$ RH & 0.205 & 3 & 0.398 & 0.755 \\
\hline Temp $\times$ RH & 2.467 & 3 & 4.790 & 0.004 \\
\hline Sex $\times$ Temp $\times R H$ & 1.013 & 3 & 1.966 & 0.125 \\
\hline Residuals & 15.453 & 90 & & \\
\hline \multicolumn{5}{|l|}{ C. cosyra } \\
\hline Intercept & 5.080 & 1 & 22.170 & $<0.001$ \\
\hline Sex & 0.455 & 1 & 1.987 & 0.162 \\
\hline Temp & 17.719 & 1 & 77.331 & $<0.001$ \\
\hline $\mathrm{RH}$ & 8.016 & 3 & 11.661 & $<0.001$ \\
\hline Initial mass & 0.756 & 1 & 3.299 & 0.073 \\
\hline Sex $\times$ Temp & 1.916 & 1 & 8.362 & 0.005 \\
\hline Sex $\times$ RH & 1.184 & 3 & 1.722 & 0.168 \\
\hline Temp $\times \mathrm{RH}$ & 18.055 & 3 & 26.266 & $<0.001$ \\
\hline Sex $\times$ Temp $\times$ RH & 1.5291 & 3 & 2.225 & 0.091 \\
\hline Residuals & 21.080 & 92 & & \\
\hline \multicolumn{5}{|l|}{ C. rosa } \\
\hline Intercept & 1.583 & 1 & 5.649 & 0.020 \\
\hline Sex & 0.336 & 1 & 1.200 & 0.276 \\
\hline Temp & 9.373 & 1 & 33.450 & $<0.001$ \\
\hline $\mathrm{RH}$ & 6.551 & 3 & 7.793 & $<0.001$ \\
\hline Initial mass & 2.948 & 1 & 10.520 & 0.002 \\
\hline Sex $\times$ Temp & 10.582 & 1 & 37.766 & $<0.001$ \\
\hline Sex $\times R H$ & 0.230 & 3 & 0.274 & 0.844 \\
\hline Temp $\times$ RH & 17.383 & 3 & 20.678 & $<0.001$ \\
\hline Sex $\times$ Temp $\times R H$ & 8.723 & 3 & 10.377 & $<0.001$ \\
\hline Residuals & 25.499 & 91 & & \\
\hline
\end{tabular}

Initial body mass was included as a covariate. Water loss rate was estimated by subtracting body water after stress for a period of 24-h from estimated initial body water (determined from initial body mass using the equations in Additional file 1: Table S1). Significant effects $(P<0.05)$ are indicated by bold type

(Fig. 4c). Water loss rate in C. capitata and C. cosyra was not associated with initial mass, but it was affected by initial mass in C. rosa (Table 4), with water loss rate of $C$. rosa becoming higher (coefficient estimate $=0.101$, s.e. $=0.031, t=3.243, p=0.002)$ as initial mass increased.

\section{Carbohydrate, glycogen, lipid and protein content}

The body composition of the three Ceratitis species that were starved at 0 or $100 \%$ relative humidity varied significantly from flies that were not stressed (Table 5). Estimates of total carbohydrate (coefficient estimate $=0.092$, s.e. $=0.037, t=2.518, p=0.016)$, glycogen (coefficient estimate $=0.009$, s.e. $=0.002, t=$ 3.996, $p<0.001$ ), total lipid (coefficient estimate $=0.011$, s.e. $=0.003 t=2.925, p=0.006)$ and total protein content (coefficient estimate $=0.093$, s.e. $=0.028, t=$ $3.338, p<0.002)$ were all positively associated with

Table 5 Minimal adequate models explaining the effects of species, sex $\mathrm{a}^{\mathrm{a}}$, and treatment on the body composition of three Ceratitis species estimated using general linear models

\begin{tabular}{|c|c|c|c|c|}
\hline Dependent variable & SS & $d f$ & $\mathrm{~F}$ & $P$ \\
\hline \multicolumn{5}{|l|}{ Carbohydrates } \\
\hline Intercept & 15.104 & 1 & 42.484 & $<0.001$ \\
\hline Treatment & 8.977 & 2 & 12.625 & $<0.001$ \\
\hline Initial mass & 2.254 & 1 & 6.338 & 0.016 \\
\hline Residuals & 14.932 & 42 & & \\
\hline \multicolumn{5}{|l|}{ Glycogen } \\
\hline Intercept & 0.001 & 1 & 1.010 & 0.321 \\
\hline Species & 0.005 & 2 & 3.140 & 0.053 \\
\hline Treatment & 0.012 & 2 & 7.323 & 0.002 \\
\hline Initial mass & 0.013 & 1 & 15.968 & $<0.001$ \\
\hline Species $\times$ Treatment & 0.010 & 4 & 2.868 & 0.034 \\
\hline Residuals & 0.036 & 43 & & \\
\hline \multicolumn{5}{|l|}{ Lipids } \\
\hline Intercept & 0.008 & 1 & 5.982 & 0.019 \\
\hline Species & 0.007 & 2 & 2.734 & 0.077 \\
\hline Sex & 0.002 & 1 & 1.733 & 0.195 \\
\hline Treatment & 0.037 & 2 & 13.891 & $<0.001$ \\
\hline Initial mass & 0.011 & 1 & 8.554 & 0.006 \\
\hline Species $\times$ Sex & 0.007 & 2 & 2.758 & 0.075 \\
\hline Species $\times$ Treatment & 0.015 & 4 & 2.907 & 0.033 \\
\hline Residuals & 0.054 & 41 & & \\
\hline \multicolumn{5}{|l|}{ Proteins } \\
\hline Intercept & 0.013 & 1 & 0.131 & 0.719 \\
\hline Species & 1.393 & 2 & 7.068 & 0.002 \\
\hline Sex & 0.096 & 1 & 0.974 & 0.329 \\
\hline Treatment & 0.301 & 2 & 1.527 & 0.229 \\
\hline Initial mass & 1.098 & 1 & 11.145 & 0.002 \\
\hline Species $\times$ Sex & 0.540 & 2 & 2.740 & 0.076 \\
\hline Sex $\times$ Treatment & 0.478 & 2 & 2.422 & 0.101 \\
\hline Residuals & 4.2372 & 43 & & \\
\hline
\end{tabular}

Initial body mass was included as a covariate to account for body size. Significant effects $(P<0.05)$ are indicated by bold type

${ }^{a}$ Sex was not included in the initial model for carbohydrates due to low sample size for males in some treatments 
initial mass. When taking initial mass into account, total carbohydrate content of the three Ceratitis species was significantly affected only by treatment (Table 5), with initial carbohydrate content of all three species being higher than when starved for $24 \mathrm{~h}$ at 0 or $100 \%$ relative humidity (Table 6). Glycogen content was significantly affected by the main effect of treatment, and the interaction of species and treatment (Table 5). Relative to initial levels, glycogen content was much higher in starved C. capitata held at $100 \%$ relative humidity. The same increase was not evident in other species. Lipid content was also affected by the main effect of treatment, and the significant interaction of species and treatment (Table 5). In this case, lipid content of $C$. capitata held at $0 \%$ relative humidity declined far more than those held at $100 \%$ relative humidity from levels estimated in control flies (Table 6). Lipid content did not vary between species in control flies, nor were there significant differences between treatments within C. cosyra or C. rosa. Protein content was significantly different between species (Table 5), with $C$. rosa containing significantly more protein than $C$. capitata, with $C$. cosyra intermediate between the other species (Table 6). In no species did protein content vary with treatment.

\section{Discussion}

Adult C. capitata are not unique in their level of desiccation resistance in comparison with the other pest
Ceratitis species included in this study. The desiccation resistance of adult $C$. cosyra was equivalent to that of $C$. capitata, despite not having become widely distributed in different parts of the world. However, adults of both C. capitata and C. cosyra were more desiccation resistant than C. rosa. These results align with those for the pupal stage of C. capitata and C. rosa, with the former resisting dehydration for longer than the latter [17], and adds to the growing literature supporting a physiological basis [19-21, 31] for the spatial partitioning of the two species at continental [15] and regional scales [32]. They also align with recent modelling that predicts the area of suitable habitat for C. rosa will decline precipitously as climate warming and drying continues in the future [33]. Given the relatively high desiccation resistance of $C$. cosyra, from the perspective of water relations it is perhaps not surprising that its distribution across central Africa and along the eastern side of the continent aligns with the tropical dry savannah climate zone [15]. What is currently unclear is the reason for $C$. cosyra being found only in the north-eastern provinces of South Africa, which is an important consideration due to its potential to spread in a changing climate. Average and maximum temperatures in South Africa have increased over the last 50 years and are predicted to continue to do so [34]. If the range of C. cosyra is delimited by temperature, it may affect more areas of the country as the climate changes. Considering the desiccation

Table 6 Body composition of three species of Ceratitis prior to and after a 24 -h period of starvation at $25{ }^{\circ} \mathrm{C}$ and $0 \%$ or $100 \%$ relative humidity

\begin{tabular}{|c|c|c|c|c|c|c|c|c|c|}
\hline \multirow{2}{*}{$\begin{array}{l}\text { Species } \\
\text { Treatment }\end{array}$} & \multicolumn{3}{|l|}{ C. capitata } & \multicolumn{3}{|l|}{ C. cosyra } & \multicolumn{3}{|l|}{ C. rosa } \\
\hline & Control & $100 \%$ r.h. & $0 \%$ r.h. & Control & 100 \% r.h. & $0 \%$ r.h. & Control & $100 \%$ r.h. & $0 \%$ r.h. \\
\hline Female & $(n=4)$ & $(n=3)$ & $(n=3)$ & $(n=7)$ & $(n=7)$ & $(n=7)$ & $(n=6)$ & $(n=7)$ & $(n=4)$ \\
\hline Fresh mass & $10.53 \pm 0.63$ & $13.60 \pm 0.21$ & $8.23 \pm 0.54$ & $11.20 \pm 0.52$ & $10.34 \pm 0.70$ & $9.59 \pm 0.29$ & $11.67 \pm 0.66$ & $16.61 \pm 1.37$ & $11.18 \pm 0.41$ \\
\hline Water & $6.00 \pm 0.68$ & $9.67 \pm 0.20$ & $5.07 \pm 0.38$ & $7.27 \pm 0.42$ & $7.26 \pm 0.50$ & $6.11 \pm 0.28$ & $7.50 \pm 0.53$ & $12.03 \pm 1.83$ & $7.45 \pm 0.35$ \\
\hline Dry mass & $4.53 \pm 0.80$ & $3.93 \pm 0.07$ & $3.17 \pm 0.18$ & $3.96 \pm 0.36$ & $3.09 \pm 0.24$ & $3.47 \pm 0.24$ & $4.17 \pm 0.40$ & $4.59 \pm 0.61$ & $3.73 \pm 0.17$ \\
\hline Carbohydrates & $0.273 \pm 0.035$ & $0.148 \pm 0.046$ & $0.153 \pm 0.014$ & $0.554 \pm 0.158$ & $0.237 \pm 0.130$ & $0.399 \pm 0.265$ & $0.401 \pm 0.166$ & $0.272 \pm 0.108$ & $0.236 \pm 0.067$ \\
\hline Glycogen & $0.049 \pm 0.007$ & $0.153 \pm 0.005$ & $0.067 \pm 0.023$ & $0.093 \pm 0.018$ & $0.047 \pm 0.015$ & $0.055 \pm 0.018$ & $0.071 \pm 0.015$ & $0.075 \pm 0.020$ & $0.101 \pm 0.008$ \\
\hline Lipids & $0.305 \pm 0.019$ & $0.255 \pm 0.030$ & $0.217 \pm 0.016$ & $0.228 \pm 0.033$ & $0.202 \pm 0.028$ & $0.217 \pm 0.020$ & $0.258 \pm 0.014$ & $0.252 \pm 0.019$ & $0.284 \pm 0.023$ \\
\hline Proteins & $0.708 \pm 0.060$ & $0.999 \pm 0.314$ & $1.284 \pm 0.201$ & $1.147 \pm 0.090$ & $1.057 \pm 0.133$ & $1.225 \pm 0.154$ & $1.382 \pm 0.205$ & $1.356 \pm 0.156$ & $1.914 \pm 0.046$ \\
\hline Male & $(n=4)$ & $(n=3)$ & $(n=4)$ & $(n=6)$ & $(n=3)$ & $(n=3)$ & $(n=5)$ & $(n=6)$ & $(n=5)$ \\
\hline Fresh mass & $8.05 \pm 0.31$ & $15.57 \pm 1.56$ & $5.88 \pm 0.19$ & $9.02 \pm 0.68$ & $6.77 \pm 0.55$ & $6.87 \pm 0.19$ & $11.04 \pm 0.86$ & $11.50 \pm 0.53$ & $8.60 \pm 0.48$ \\
\hline Water & $4.68 \pm 0.35$ & $12.10 \pm 1.33$ & $3.90 \pm 0.27$ & $6.52 \pm 0.66$ & $4.87 \pm 0.64$ & $4.53 \pm 0.27$ & $6.96 \pm 0.56$ & $7.95 \pm 0.37$ & $4.56 \pm 0.31$ \\
\hline Dry mass & $3.38 \pm 0.58$ & $3.47 \pm 0.28$ & $1.98 \pm 0.15$ & $2.63 \pm 0.28$ & $1.90 \pm 0.10$ & $2.33 \pm 0.12$ & $4.08 \pm 0.37$ & $3.55 \pm 0.49$ & $4.04 \pm 0.47$ \\
\hline Carbohydrates & $0.538 \pm 0.138$ & $0.135 \pm 0.032$ & $0.088 \pm 0.006$ & $0.206^{a}$ & $0.080 \pm 0.017$ & $0.298 \pm 0.209$ & $0.437^{\mathrm{a}}$ & $0.220 \pm 0.105$ & $0.083^{\mathrm{a}}$ \\
\hline Glycogen & $0.029 \pm 0.009$ & $0.153 \pm 0.005$ & $0.052 \pm 0.021$ & $0.057 \pm 0.019$ & $0.023 \pm 0.013$ & $0.035 \pm 0.012$ & $0.090 \pm 0.025$ & $0.101 \pm 0.023$ & $0.075 \pm 0.008$ \\
\hline Lipids & $0.256 \pm 0.013$ & $0.229 \pm 0.016$ & $0.150 \pm 0.027$ & $0.148 \pm 0.018$ & $0.154 \pm 0.010$ & $0.191 \pm 0.010$ & $0.225 \pm 0.015$ & $0.191 \pm 0.019$ & $0.218 \pm 0.024$ \\
\hline Proteins & $0.769 \pm 0.202$ & $0.791 \pm 0.240$ & $0.696 \pm 0.131$ & $0.952 \pm 0.130$ & $1.065 \pm 0.153$ & $0.999 \pm 0.052$ & $1.019 \pm 0.158$ & $1.274 \pm 0.141$ & $1.207 \pm 0.052$ \\
\hline
\end{tabular}

Values are the mean \pm 1 s.e., in milligrams. Fresh mass of flies held at $100 \%$ r.h. and $0 \%$ r.h. is fly mass after starvation for $24 \mathrm{~h}$ under each environmental condition

${ }^{\text {a }}$ Sample size $=1$ 
resistance of adults, the associated drying that is also predicted [34,35] will likely be of little consequence for C. cosyra. However, as $C$. cosyra has relatively few known host plant species, usually utilising fruit of plants in the Anacardiaceae and Annonaceae, climate change may have little effect on their southern distribution unless these hosts are cultivated or southern populations adapt to utilise alternative hosts. The latter situation is not unlikely due to the well-studied cases of host race evolution in tephritid flies (e.g., [36-39]).

The mechanisms that have evolved to increase the desiccation resistance of $C$. capitata and C. cosyra are not consistent. The data suggest that the desiccation resistance of $C$. capitata is derived from relatively high dehydration tolerance and low rates of water loss that are unaffected by atmospheric vapour pressure. In addition, it seems likely that $C$. capitata metabolises lipid reserves during periods of water stress (but not during starvation). Lipid content of adult $C$ capitata not subjected to any stress was also higher than that of the other species. Lipid content has sometimes been associated with improved desiccation resistance in Drosophila species [24], but in other studies on Drosophila, laboratory selection for desiccation resistance has led to reduced [40] or no change in [41] lipid content. Like C. capitata, the adults of the xeric-adapted tsetse, Glossina pallidipes Austen, exhibited a marked decline in lipid content when starved at $0 \%$ relative humidity relative to those stressed at $99 \%$ relative humidity (at $25{ }^{\circ} \mathrm{C}$; [42]). Lipid catabolism has been noted during desiccation in desert beetles, leading to the production of metabolic water [26, 43-45], but beetles and other insects from more mesic habitats, where water is freely available, have not been found to exhibit this capability $[26,42,46]$.

Mechanisms for the relatively high desiccation resistance of $C$. cosyra are not as evident from the assays performed in this study. Water loss rate of C. cosyra was lower than in C. rosa, but still higher than in C. capitata, especially at high vapour pressure deficits. It remains to be determined how $C$. capitata and C. cosyra achieve lower rates of water loss than C. rosa; detailed study of water loss via the cuticle, spiracles and excretion, and cuticular lipid composition, are required to establish this. Neither C. capitata nor C. cosyra had more body water, nor were they more tolerant of dehydration than C. rosa. On the contrary, C. capitata had lower body water than C. rosa despite being more desiccation resistant. This result is surprising because in other tephritid flies $[28,30]$ as well as other model insect systems [23, 26, 42, 47] enhanced desiccation resistance has been associated with higher body water content. Under saturated conditions, water at death increased and water loss rates became negative in C. cosyra and C. rosa. It is highly likely that this was caused by the drinking of condensation by starved flies, but may have also resulted from gains in water content from metabolism or passive sorption of water from the atmosphere [48].

Temperature was an important determinant of how adults of the tested Ceratitis species were able to tolerate differences in humidity. In all species, lower survival times and higher rates of water loss, and lower dehydration tolerance were observed at higher temperatures when flies were exposed to unsaturated atmospheric conditions. These results differ somewhat from those reported for the adults of four Glossina species, where water loss rates in relation to relative humidity and temperature were not consistent across the species [42]. Higher rates of water loss at higher temperatures in $C$. cosyra and C. rosa may be associated with lower melting points of waterproofing cuticular lipids, resulting in higher rates of cuticular water loss [23]. Males of $C$. cosyra are smaller than females, so rates of water loss after having been adjusted for initial mass of males should be higher assuming that they have a lower surface area-volume ratio. Another possibility not accounted for in the design of this study is that male activity within tubes may have been higher than that of females, leading to higher water loss via the respiratory pathway. Female and male B. tryoni [49] and Drosophila melanogaster Meigen [50] of the same age exhibit different patterns of spontaneous activity, which has been interpreted to reflect differences in life history and physiological requirements of the sexes.

Unlike the other tested species, when held at $100 \%$ relative humidity, water loss rates of $C$. capitata were higher at $30{ }^{\circ} \mathrm{C}$ than at the benign temperature of $25^{\circ} \mathrm{C}$. This result, together with lower variation in desiccation resistance and dehydration tolerance in response to relative humidity at $25^{\circ} \mathrm{C}$, suggests that some of the invasive potential of $C$. capitata does not stem from a more plastic response to desiccating conditions, as would be predicted by the greater flexibility hypothesis [51]. Baker HG [51] proposed that invasive species have greater plasticity than indigenous ones, which enables their survival under novel conditions. In an explicit test of this hypothesis, Chown et al. [3] found for springtails on Marion Island that flexibility in the response of indigenous and invasive species to acclimation did not differ, but rather acclimation at warmer temperatures led to improved desiccation resistance at both test temperatures. An ability to maintain fitness under stressful conditions was found in the invasive slug, Arion lusitanicus (Mabille), where high fecundity under conditions of limited food and high temperatures were retained relative to an indigenous congener [52]. In contrast to this "Jackof-all-trades" phenotype [53], C. capitata appears to have a consistent basal resistance to water stress under benign thermal conditions relative to conspecifics. Using 
the terminology of Richards CL, Bossdorf O, Muth NZ, Gurevitch J and Pigliucci M [53], C. capitata is rather a "Master of some" with regard to water stress, and better able to increase fitness in favourable environments. This response under stressful conditions is important for the establishment of $C$. capitata in new areas, and links well with models that predict its potential distribution. A model for world-wide seasonal suitability for C. capitata developed by Szyniszewska AM and Tatem AJ [12] was principally driven by minimum land surface temperature, followed by maximum land surface temperature, elevation, then maximum rainfall. Assuming no negative biotic interactions with other tephritid species, our results indicate that $C$. capitata will largely be able to withstand water stress as long as the thermal environment in a newly colonised area is suitable.

Across the Ceratitis species tested, adult dehydration tolerance was lower in females. This result is similar to those reported for the Mexican fruit fly, Anastrepha ludens Loew [28] and B. tryoni $[29,30]$. It has been proposed that reduced dehydration tolerance in female tephritid flies is a result of gravid females not having access to the pool of water contained within developing eggs $[28,30]$, and this is also a likely scenario for the Ceratitis species studied here because they were tested at an age (10 days after adult emergence) when they are known to be sexually mature if fed a nutritious diet [54]. Given this, it is surprising that there was no effect of sex on the lipid or protein content of the three Ceratitis species. It is not unrealistic to expect that gravid females should have a higher lipid content of these nutrients due to their investment in eggs. Inability to detect this effect may reflect the differential investment of nutrients for different life history strategies between the sexes, as found in C. capitata [55].

\section{Conclusion}

In conclusion, tolerance of water stress by adults is likely to play a role in the invasive success of $C$. capitata. They exhibit relatively high levels of desiccation resistance that is associated with high tolerance of water loss, low rates of water loss, storage of lipids, and the ability to catabolise lipids during periods of water stress, which are particularly beneficial at benign temperatures. Relative to C. rosa, these properties would enable survival of adult C. capitata in drier environments so that they are able to reproduce and become established when conditions become more favourable. However, tolerance of water stress alone is not sufficient to explain why C. cosyra has not become as widespread as $C$. capitata. The interaction of temperature with water stress, as well as the influence of host availability are likely important in proscribing the distribution of C. cosyra.

\section{Methods}

\section{Source of flies and culture maintenance}

Flies of each species tested in this experiment, $C$. capitata, C. cosyra and C. rosa, were initially sourced from large, outbred laboratory populations maintained by Citrus Research International, Nelspruit, South Africa. The cultures of each species are maintained at CRI in high numbers and have been maintained in the laboratory for nearly 200 generations. The cultures are regularly supplemented with wild flies caught during summer to minimise inbreeding (wild males are paired with laboratory females) and are held indoors under buffered, but variable temperatures $\left(25 \pm 4{ }^{\circ} \mathrm{C}\right)$ with natural lighting. While the tested cultures have been held in the laboratory for a long period of time, these cultures have been used to test differences in the thermal tolerance of C. capitata and C. rosa [56], and as in those studies, water balance traits should represent baseline genotypic differences between the species. Eggs laid by females are placed on a carrot-based medium in which larvae develop. Pupae were transported to the University of Pretoria by road in a cooler box. On arrival at the University of Pretoria, pupae of each species were placed into separate plastic cages (volume $5 \mathrm{~L}$ ) and kept in a climate room at $25 \pm 1{ }^{\circ} \mathrm{C}$ until they emerged. On adult emergence, approximately 300 adults of each species (mixed sexes) were transferred to separate 5-L plastic cages furnished with sugar and yeast extract powder (Biolab, Merck, Wadeville, Gauteng, South Africa) in separate dishes for food, and a container of watersoaked cotton wool.

Ten days after adult emergence, oviposition dishes were placed in each cage into which females could lay eggs. Oviposition dishes were circular plastic cups (Volume Injection Products, East London, Eastern Cape, South Africa) with a volume of $125 \mathrm{~mL}$ that contained one sheet of tissue paper that had been sprayed with distilled water. To the damp tissue, $2 \mathrm{~mL}$ of guava concentrate (Elvin Food and Beverages, East London, Eastern Cape, South Africa) was applied with a $3 \mathrm{~mL}$ graduated plastic Pasteur pipette (Delta Lab, Barcelona, Spain). The opening of the plastic container was covered with a double layer of laboratory film (Parafilm M, Bemis Flexible Packaging, Neenah, WI, USA) that was then pierced 10-15 times with an entomological pin. Eggs laid by female $C$. capitata, C. cosyra and C. rosa into the oviposition dishes were rinsed, separately, from the laboratory film and container with distilled water from a wash bottle into a flat-bottomed glass evaporating dish. Eggs in water were concentrated in the evaporating dish by gently swirling the contents into the centre. Eggs were then transferred with a plastic Pasteur pipette to $500 \mathrm{~mL}$ of the same carrot-based medium used by Citrus Research International for larval development (no more than 600 eggs $/ 500 \mathrm{~mL}$ ). To avoid 
contamination of each culture, the evaporating dish was washed with boiling water between each Ceratitis species and a new plastic Pasteur pipette was used. Containers of larval rearing medium with eggs were placed in clear plastic trays with ventilated lids that were lined with a layer of washed, dry beach sand to a depth of $10 \mathrm{~mm}$. At the end of the third larval instar, larvae 'hopped' from the larval rearing medium and entered the pupal phase in the layer of sand. The sand was sifted to recover the pupae, which were then returned to the culture or directed to experiments.

Ceratitis capitata, C. cosyra and C. rosa pupae used for experiments ( 300 of each species) were placed in separate $5 \mathrm{~L}$ plastic cages with sources of food (sugar, hydrolysed yeast powder) and water. This was a low cage stocking density (surface area of $\sim 6.5 \mathrm{~cm}^{2}$ per fly, not taking into consideration additional area from food and water containers within the cage) to prevent potential negative interactions at higher density [57]. On adult emergence, all cages were then inserted into clear plastic bags that were sealed to maintain high humidity (>90\%) and ensure that flies were well hydrated, and kept in a laboratory maintained at $25 \pm 1{ }^{\circ} \mathrm{C}$. Two cohorts of each species were required to complete the study, with one cohort per test temperature $\left(25\right.$ or $\left.30{ }^{\circ} \mathrm{C}\right)$.

\section{Initial condition}

At 10 days after adult emergence, 20 flies of each species (10 females and 10 males) were placed in pre-weighed $2 \mathrm{~mL}$ microcentrifuge tubes of known weight. The initial mass of each fly was measured (to $0.1 \mathrm{mg}$; AR0640, Ohaus Corporation, Pine Brook, NJ, USA) before storage in a freezer at $-20{ }^{\circ} \mathrm{C}$. At a later time, these flies were dried in a fan-forced laboratory oven at $60{ }^{\circ} \mathrm{C}$ for $96 \mathrm{~h}$ and weighed on a microbalance (to $0.001 \mathrm{mg}$; CPA2P, Sartorius AG, Goettingen, Germany) to determine body water and dry mass. Initial mass of these flies was determined using an analytical balance rather than a microbalance to minimise the time required to weigh them and thereby reduce measurement bias introduced by handling time. Ordinary least squares regression was used to relate initial mass to initial body water content for each species, sex and cohort (test temperature). Linear regression provided the best fit for all relationships when compared with non-linear functions. The resulting regression equations (Additional file 1: Table S1) were used to estimate initial body water based on measurements of initial mass in subsequent experiments.

\section{Desiccation resistance and dehydration tolerance}

At 10 days after adult emergence, 40 females and 40 males of each species were placed into individual, numbered, pre-weighed $2 \mathrm{~mL}$ microcentrifuge tubes pierced with 12 holes (approximate diameter $=1 \mathrm{~mm}$ ). Flies in tubes were then weighed (to $0.1 \mathrm{mg}$ ) and initial mass of each fly was calculated by subtracting tube mass. Ten females and 10 males of each species were then allocated to one of four humidity treatments: $0 \%, 33 \%, 75 \%$ and $100 \%$. Relative humidity was manipulated by placing plastic cups with $200 \mathrm{~mL}$ of silica gel, saturated magnesium chloride solution, saturated sodium chloride solution or deionised water, respectively, in clear plastic airtight boxes (volume 4.5 L; Ref 02 1474, Hobby Life ${ }^{\circ}$, Demirel Plastik, Turkey). Actual values for relative humidity recorded with Thermochron iButtons (DS1921G, Maxim Integrated, San Jose, CA, USA) in each treatment were: $0 \%$ : $-1.29 \pm 0.14 \%$ (at $25.12 \pm 0.01{ }^{\circ} \mathrm{C}$ ); $33 \%: 33.38 \pm 0.06 \%$ (at $24.95 \pm 0.01{ }^{\circ} \mathrm{C}$ ); $75 \%: 75.55 \pm$ $0.11 \%$ (at $25.24 \pm 0.01{ }^{\circ} \mathrm{C}$ ); $100 \%: 99.27 \pm 0.16 \%$ (at $25.11 \pm 0.01{ }^{\circ} \mathrm{C}$ ). All airtight boxes were maintained at $25{ }^{\circ} \mathrm{C}$ for the duration of the experiment by placing them in an incubator. The experiment was then repeated at $30{ }^{\circ} \mathrm{C}$ using a second cohort of flies. Actual values for relative humidity recorded in the airtight boxes during these treatments were: $0 \%$ : $-0.59 \pm 0.11 \%$ (at $29.05 \pm$ $0.02{ }^{\circ} \mathrm{C}$ ); $33 \%: 33.69 \pm 0.04 \%$ (at $29.41 \pm 0.01{ }^{\circ} \mathrm{C}$ ); $75 \%$ : $76.17 \pm 0.07 \%$ (at $30.11 \pm 0.01{ }^{\circ} \mathrm{C}$ ); $100 \%$ : $100.70 \pm$ $0.07 \%$ (at $29.01 \pm 0.02{ }^{\circ} \mathrm{C}$ ).

Desiccation resistance was defined as the time that elapsed before death. All tubes were checked for mortality every $3 \mathrm{~h}$ by viewing them through the clear plastic top of the airtight boxes. Dead flies were removed from their tubes, weighed (to $0.01 \mathrm{mg}$ ), returned to their tubes and stored in a freezer at $-20{ }^{\circ} \mathrm{C}$. Removal of tubes required that the airtight boxes be unsealed, but iButton recordings indicated a rapid return to experimental conditions after this disturbance. Later, all flies were dried and weighed as described above to determine body water and dry mass at death. Dehydration tolerance, defined as water loss before death, was calculated by subtracting body water at death from estimated initial body water (following the relationships in Additional file 1: Table S1).

\section{Water loss rate}

At 10 days after adult emergence, 30 females and 30 males of each species were placed into pierced microcentrifuge tubes and their initial mass was determined as above. Fifteen flies were then allocated to one of four humidity treatments, as above. After $24 \mathrm{~h}$ at $25{ }^{\circ} \mathrm{C}$, flies were removed from each humidity treatment, weighed in their vials (to $0.1 \mathrm{mg}$ ) to calculate weight loss, and then placed in a freezer at $-20{ }^{\circ} \mathrm{C}$. Flies were then dried and weighed, as above, to determine body water and dry mass after $24 \mathrm{~h}$. Water loss rate $\left(\mathrm{mg} \mathrm{day}^{-1}\right)$ was calculated by subtracting body water after $24 \mathrm{~h}$ from estimated initial body water (following the relationships in Additional file 1: Table S1). The experiment was then repeated at $30{ }^{\circ} \mathrm{C}$. 
Carbohydrate, glycogen, lipid and protein content assays Adult flies were obtained for the determination of lipid, free sugar, glycogen and protein content by repeating the desiccation resistance and dehydration tolerance experiments. This was necessary because values for carbohydrate and protein content were negatively affected by oven-drying of flies at $60{ }^{\circ} \mathrm{C}$. Levels of relative humidity achieved during these repeats were measured with Thermochron iButtons (0\%: $-0.43 \pm 0.50 \%$ at $24.34 \pm 0.70{ }^{\circ} \mathrm{C} ; 100 \%: 73.16 \pm 2.86 \%$ at $\left.23.88 \pm 0.47{ }^{\circ} \mathrm{C}\right)$. For each species, control flies were weighed on an electronic microbalance (MS104S, Mettler Toledo, Greifensee, Switzerland) and immediately frozen at $-80{ }^{\circ} \mathrm{C}$, and additional flies were subjected to either $0 \%$ or $100 \%$ relative humidity $\left(25{ }^{\circ} \mathrm{C}\right)$ for $24 \mathrm{~h}$. Flies were weighed before and after each treatment (to $0.1 \mathrm{mg}$ ) before being frozen. Flies were freeze-dried to obtain dry mass and thereby water content, and refrozen at $-80{ }^{\circ} \mathrm{C}$.

Protein, carbohydrate, glycogen and total lipid contents were obtained from each individual insect for each species (aiming to assay a minimum of 6 for each control/treatment: 3 male, 3 female) using colourimetric methods developed by Bradford MM [58] and van Handel [59-61] and modified into a microplate format by Foray V, Pelisson P-F, Bel-Venner M-C, Desouhant E, Venner S, Menu F, Giron D and Rey B [62]. Where modifications to the methods described by Foray $\mathrm{V}$, Pelisson P-F, Bel-Venner M-C, Desouhant E, Venner S, Menu F, Giron D and Rey B [62] were made, the procedure is described in detail below. Sugar and glycogen samples were run in duplicate on the plate, while protein and lipid samples were run in triplicate. Absorbance values were averaged to obtain one absorbance value per biological sample. In all cases, a flatbottom 96-well borosilicate microplate (730.009QG, Hellma Analytics, Germany) was used, and absorbance was read using a microplate reader (BioTek Powerwave 340) and Gen $5^{\mathrm{TM}}$ v.1.05.11 software (both BioTek Instruments, Inc.). Each species was assayed on a separate day and standards were used to compare between species.

Whole flies were homogenized in $180 \mu \mathrm{L}$ lysis buffer (100 mM KH $\mathrm{PO}_{4}, 1 \mathrm{mM}$ DTT, $1 \mathrm{mM}$ EDTA, pH 7.4) for $20 \mathrm{~s}$ at $25 \mathrm{~Hz}$ using a mixer mill (MM 400, Retsch, Germany). The protein content was determined by gently centrifuging the homogenate and adding $1.5 \mu \mathrm{L}$ of the supernatant or $2 \mathrm{mg} / \mathrm{ml}$ albumin standard (23209, Thermo Scientific) dissolved in lysis buffer to each well. $250 \mu \mathrm{L}$ of Bradford micro-assay reagent (B6916, Sigma) was added to each well and incubated at room temperature for $20 \mathrm{~min}$ before absorbance was read at $595 \mathrm{~nm}$. Lipids and soluble carbohydrates were extracted by adding $20 \mu \mathrm{L} 20 \%$ sodium sulfate, $4.5 \mu \mathrm{L}$ of lysis buffer and $1500 \mu \mathrm{L}$ chloroform methanol (1:2 v/v) solution to the homogenate. The homogenate was vortexed and centrifuged at $180 \mathrm{~g}$ for $15 \mathrm{~min}\left(4{ }^{\circ} \mathrm{C}\right)$. The supernatant containing the carbohydrates and lipids was transferred to a new tube, while the glycogen pellet was kept. Glycogen was extracted from the pellet following Yuval B, Kaspi R, Shloush S and Warburg MS [63]. The pellet was washed twice with $400 \mu \mathrm{L} 80 \%$ methanol and centrifuged at $16000 \mathrm{~g}$ for $5 \mathrm{~min}\left(4^{\circ} \mathrm{C}\right)$. After removing the

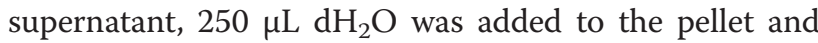
heated at $70{ }^{\circ} \mathrm{C}$ for $5 \mathrm{~min} .1 \mathrm{~mL}$ fresh anthrone reagent (319899, Sigma; $1.42 \mathrm{~g} / \mathrm{L}$ ) was added to $200 \mu \mathrm{L}$ of sample or standard $(1 \mathrm{mg} / \mathrm{ml}$ glucose $(\mathrm{D}+)$ dissolved in $\mathrm{dH}_{2} \mathrm{O}$, SAAR2676020EM, Merck, South Africa) and incubated at $90{ }^{\circ} \mathrm{C}$ for $10 \mathrm{~min}$. The reaction was stopped by cooling the sample on ice before $200 \mu \mathrm{L}$ of sample was added to each well and the absorbance was read at $625 \mathrm{~nm}$. Total water soluble carbohydrates were determined following Foray V, Pelisson P-F, Bel-Venner M-C, Desouhant E, Venner S, Menu F, Giron D and Rey B [62]. Fresh anthrone reagent was used to induce a colourimetric reaction measured at $625 \mathrm{~nm}$. The standard from the glycogen step was used to quantify the amount of sugar present see [64]. The total lipid content was determined using vanillin reagent (V1104, Sigma) with triolein (44895, Sigma) as the standard, following Foray V, Pelisson P-F, Bel-Venner M-C, Desouhant E, Venner S, Menu F, Giron D and Rey B [62]. Absorbance was measured spectrophotometrically at $525 \mathrm{~nm}$.

Absorbance values were converted to mg amounts using standard curves. The amount of each nutrient present in each total fly was estimated. All estimates of total water soluble carbohydrates higher than $1 \mathrm{mg}$ were deleted, as were estimates of glycogen that were greater than $0.2 \mathrm{mg}$. In the case of total carbohydrates, this led to the exclusion of two $C$. capitata, fifteen $C$. cosyra, and eighteen $C$. rosa from data analysis.

\section{Data analyses}

All data analyses were performed using the $\mathrm{R}$ v. 3.1.2 statistical environment ( $\mathrm{R}$ Development Core Team, 2012). Body mass and body water were compared between species using linear models. Predictor variables in each model were species, sex and their interaction. In the model for body water, body mass was included as a covariate. Model-checking plots were inspected and revealed that the models did not violate assumptions of constancy of variance and normality of errors. Least squares means of the response variable for these and all models described below were determined using the 'predict' function in $\mathrm{R}$ with covariates at their mean.

Parametric survival regression with Weibull agespecific hazards was performed using the 'survival' library of $\mathrm{R}$ to determine the effect of species, sex, temperature and relative humidity on desiccation resistance. Initial body mass was included as a covariate in 
the model to account for differences in the pool of available water in each individual or size effects on body composition. The minimal adequate model was determined based on Akaike's information criterion (AIC) using the 'step' function in R, which involves the step-wise deletion of the least influential parameters from the model. Because significant effects of species or an interaction with species were found for desiccation resistance, models were run separately for each species with sex, temperature and relative humidity as predictor variables.

The effects of species, sex, temperature and relative humidity and their interactions on dehydration tolerance and water loss rate were determined using linear models. In the case of dehydration tolerance, the dependent variable was body water at death, which was related to estimated body water by inclusion of the latter as a covariate in the model. In the model for water loss rate, initial mass was included as a covariate because body mass has been previously shown to correlate strongly with water loss [30]. In both cases, there was a significant four-way interaction between species, sex, temperature and relative humidity, so the models were run separately for each species before being simplified based on comparison of AIC values. Flies that died during the water loss rate assay were excluded from analysis. These models did not violate the assumptions of constancy of variance and normality of errors.

Carbohydrate, glycogen, lipid and protein content in flies not subjected to stress, and either desiccated or starved were compared using linear models. Predictor variables in the initial model for carbohydrate content included only species and treatment (i.e., initial condition, $24 \mathrm{~h}$ at $0 \%$ relative humidity, $24 \mathrm{~h}$ at $100 \%$ relative humidity), their interaction, and initial mass. Sex was not included in this model due to there being too few reliable estimates of carbohydrate content from each sex in the three species. Values for carbohydrate content were log-transformed to improve model fit. The initial linear models for glycogen, lipid and protein content included sex and its interactions with species and treatment, with initial mass as a covariate. Initial mass rather than dry mass was used as a covariate in these models because we wished to establish how body composition varied relative to the initial condition of each fly rather than its condition after a period of stress. Models were simplified based on comparison of AIC values.

\section{Additional files}

Additional file 1: Table S1. Linear regression for the relationship between body mass $(\mathrm{mg})$ and body water content $(\mathrm{mg})$ for cohorts of three Ceratitis species that were subsequently tested for desiccation resistance and water loss rate at two temperatures. The equation for each relationship was used to estimate initial body water content from initial body mass for flies subjected to desiccation and water loss rate assays. (DOC $41 \mathrm{~kb}$ )

Additional file 2: Table S2. Analysis of deviance table for the final fitted parametric survival model that describes desiccation resistance of three Ceratitis species with respect to species, sex, temperature (Temp) and relative humidity $(\mathrm{RH})$. Initial body mass was included as a covariate in the model. Data were fitted to a Weibull hazard function. Type III likelihood ratio tests were used to construct the analysis of deviance table. Significant effects $(P<0.05)$ are indicated by bold type. (DOC $34 \mathrm{~kb}$ )

Additional file 3: Table S3. General linear model for the relationship between species, sex, temperature (Temp) and relative humidity $(\mathrm{RH})$ on the dehydration tolerance of three Ceratitis species. Estimated body water (determined from initial body mass using the equations in Table S1) was included as a covariate. Significant effects $(P<0.05)$ are indicated by bold type. (DOC $37 \mathrm{~kb}$ )

Additional file 4: Table S4. General linear model for the relationship between species, sex, temperature (Temp) and relative humidity ( $\mathrm{RH}$ ) on water loss rate of three Ceratitis species. Initial mass was included as a covariate. Significant effects $(P<0.05)$ are indicated by bold type. (DOC $37 \mathrm{~kb}$ )

\section{Competing interests}

The authors declare that they have no competing interests.

\section{Authors' contributions}

CWW and JST conceived and designed the study. CWW reared experimental animals and analysed the data. CWW and DM performed desiccation resistance and water loss rate assays. Biochemical assays were performed by LB. All authors contributed to the preparation of the manuscript. All authors read and approved the final manuscript.

\section{Acknowledgments}

We thank Arné Verhoef for assistance with set-up of desiccation resistance assays, and Marna Ferreira for placing orders for consumables. Wilmari Uys assisted with replicating treatments to generate samples for biochemical analyses. The Department of Biochemistry at Stellenbosch University and Stefan Hayward provided access to and technical assistance for the microplate reader. Sue Nicolson provided constructive feedback on a draft of the manuscript.

\section{Funding}

The study was enabled by a University of Pretoria Research Development Programme grant awarded to CWW. JST was supported by NRF Incentive Funding and the Centre for Invasion Biology. Key laboratory equipment was obtained from funding through HortGro Science and Sub-Committee B grants. LB was supported by an NRF Innovation Postdoctoral Fellowship. DM was awarded a University of Pretoria Postdoctoral Fellowship.

\section{Author details}

${ }^{1}$ Department of Zoology and Entomology, University of Pretoria, Private Bag X20, Hatfield 0028?A3B2 show , ?]South Africa. ${ }^{2}$ Centre for Invasion Biology, Department of Conservation Ecology and Entomology, Stellenbosch University, Private Bag X1, Matieland 7602, South Africa. ${ }^{3}$ Present address: Department of Entomology and Nematology, University of Florida, PO Box 110620, Gainesville, FL 32611-0620, USA. ${ }^{4}$ Present address: School of Animal, Plant and Environmental Sciences, University of the Witwatersrand, 1 Jan Smuts Avenue, Braamfontein 2000,South Africa.

Received: 5 October 2015 Accepted: 22 March 2016

Published online: 31 March 2016

\section{References}

1. Lee CE. Evolutionary genetics of invasive species. Trens Ecol Evol. 2002;17: 386-91.

2. Sakai AK, Allendorf FW, Holt JS, Lodge DM, Molofsky J, With KA, et al. The population biology of invasive species. Annu Rev Ecol Syst. 2001;32:305-32. 
3. Chown SL, Slabber S, McGeoch MA, Janion C, Leinaas HP. Phenotypic plasticity mediates climate change responses among invasive and indigenous arthropods. Proc R Soc B. 2007;274:2531-7.

4. De Meyer M. Systematic revision of the subgenus Ceratitis MacLeay s.s. (Diptera: Tephritidae). Zool J Linn Soc. 2000;128:439-67.

5. Malacrida AR, Gomulski LM, Bonizzoni M, Bertin S, Gasperi G, Guglielmino CR. Globalization and fruit fly invasion and expansion: the medfly paradigm. Genetica. 2007:131:1-9.

6. Diamantidis AD, Carey JR, Nakas CT, Papadopoulos NT. Population-specific demography and invasion potential in medfly. Ecol Evol. 2011;1:479-88.

7. Gasperi G, Bonizzoni M, Gomulski LM, Murelli V, Torti C, Malacrida AR, et al. Genetic differentiation, gene flow and the origin of infestations of the medfly, Ceratitis capitata. Genetica. 2002;116:125-35.

8. Karsten M, van Vuuren JB, Addison P, Terblanche JS, Leung B. Deconstructing intercontinental invasion pathway hypotheses of the Mediterranean fruit fly (Ceratitis capitata) using a Bayesian inference approach: are port interceptions and quarantine protocols successfully preventing new invasions? Divers Distrib. 2015;21:813-25.

9. Vera MT, Rodriguez R, Segura DF, Cladera JL, Sutherst RW. Potential geographical distribution of the Mediterranean fruit fly, Ceratitis capitata (Diptera: Tephritidae), with emphasis on Argentina and Australia. Environ Entomol. 2002;31:1009-22.

10. De Meyer M, Robertson MP, Peterson AT, Mansell MW. Ecological niches and potential geographical distributions of Mediterranean fruit fly (Ceratitis capitata) and Natal fruit fly (Ceratitis rosa). J Biogeog. 2008;35:270-81.

11. Papadopoulos NT, Plant RE, Carey JR. From trickle to flood: the large-scale, cryptic invasion of California by tropical fruit flies. Proc R Soc B. 2013;280: 20131466.

12. Szyniszewska AM, Tatem AJ. Global assessment of seasonal potential distribution of Mediterranean fruit fly, Ceratitis capitata (Diptera: Tephritidae) PLOS ONE. 2014;9, e111582

13. De Meyer M, Copeland RS, Lux SA, Mansell M, Quilici S, Wharton R, et al. Annotated check list of host plants for Afrotropical fruit flies (Diptera: Tephritidae) of the genus Ceratitis. Documentations Zoologiques Musee Royal de I'Afrique Centrale. 2002;27:1-91.

14. Siebert JB, Cooper T. Embargo on California produce would cause revenue, job loss. Calif Agric. 1995;49:7-12.

15. De Meyer M. Distribution and host-plant relationships within the genus Ceratitis MacLeay (Diptera: Tephritidae) in Africa. Cimbebasia. 2001:17:219-28

16. Duyck PF, David P, Quilici S. A review of relationships between interspecific competition and invasions in fruit flies (Diptera: Tephritidae). Ecol Entomol. 2004;29:511-20.

17. Duyck PF, David P, Quilici S. Climatic niche partitioning following successive invasions by fruit flies in La Réunion. J Anim Ecol. 2006;75:518-26.

18. Duyck PF, Quilici S. Survival and development of different life stages of three Ceratitis spp. (Diptera: Tephritidae) reared at five constant temperatures. Bull Entomol Res. 2002;92:461-9.

19. Nyamukondiwa C, Terblanche JS. Thermal tolerance in adult Mediterranean and Natal fruit flies (Ceratitis capitata and Ceratitis rosa): Effects of age, gender and feeding status. J Therm Biol. 2009;34:406-14.

20. Nyamukondiwa C, Terblanche JS. Within-generation variation of critical thermal limits in adult Mediterranean and Natal fruit flies Ceratitis capitata and Ceratitis rosa: thermal history affects short-term responses to temperature. Physiol Entomol. 2010;35:255-64.

21. Nyamukondiwa C, Weldon CW, Chown SL, le Roux PC, Terblanche JS. Thermal biology, population fluctuations and implications of temperature extremes for the management of two globally significant insect pests. J Insect Physiol. 2013;59:1199-211.

22. Chown SL, Nicolson SW. Insect Physiological Ecology: mechanisms and patterns. New York: Oxford University Press; 2004.

23. Gibbs AG, Chippindale AK, Rose MR. Physiological mechanisms of evolved desiccation resistance in Drosophila melanogaster. J Exp Biol. 1997:200:1821-32

24. Telonis-Scott M, Guthridge KM, Hoffmann AA. A new set of laboratory-selected Drosophila melanogaster lines for the analysis of desiccation resistance: response to selection, physiology and correlated responses. J Exp Biol. 2006; 209:1837-47.

25. Chown SL, Le Lagadec MD, Scholtz CH. Partitioning variance in a physiological trait: desiccation resistance in keratin beetles (Coleoptera, Trogidae). Funct Ecol. 1999;13:838-44.
26. Le Lagadec MD, Chown SL, Scholtz CH. Desiccation resistance and water balance in southern African keratin beetles (Coleoptera, Trogidae): the influence of body size and habitat. J Comp Physiol B. 1998;168:112-22.

27. Gibbs AG, Fukuzato F, Matzkin LM. Evolution of water conservation mechanisms in Drosophila. J Exp Biol. 2003;206:1183-92.

28. Tejeda MT, Arredondo J, Pérez-Staples D, Ramos-Morales P, Liedo P, Díaz-Fleischer F. Effects of size, sex and teneral resources on the resistance to hydric stress in the tephritid fruit fly Anastrepha ludens. Insect Physiol. 2014;70:73-80.

29. Weldon CW, Taylor PW. Desiccation resistance of adult Queensland fruit flies Bactrocera tryoni decreases with age. Physiol Entomol. 2010;35:385-90.

30. Weldon CW, Yap S, Taylor PW. Desiccation resistance of wild and mass-reared Bactrocera tryoni (Diptera: Tephritidae). Bull Entomol Res. 2013;103:690-9

31. Nyamukondiwa C, Kleynhans E, Terblanche JS. Phenotypic plasticity of thermal tolerance contributes to the invasion potential of Mediterranean fruit flies (Ceratitis capitata). Ecol Entomol. 2010;35:565-75.

32. Manrakhan A, Addison P. Assessment of fruit fly (Diptera: Tephritidae) management practices in deciduous fruit growing areas in South Africa. Pest Manage Sci. 2014;70:651-60.

33. Hill MP, Bertelsmeier C, Clusella-Trullas S, Garnas J, Robertson MP, Terblanche JS. Predicted decrease in global climate suitability masks regional complexity of invasive fruit fly species response to climate change. Biol Invasions. 2016. doi:10.1007/s10530-016-1078-5.

34. MacKellar N, New M, Jack C. Observed and modelled trends in rainfall and temperature for South Africa: 1960-2010. S Afr J Sci. 2014. doi:10.1590/sajs. 2014/20130353.

35. Engelbrecht FA, Landman WA, Engelbrecht CJ, Landman S, Bopape MM, Roux B, et al. Multi-scale climate modelling over Southern Africa using a variable-resolution global model. Water SA. 2011:37.

36. Brown JM, Abrahamson WG, Way PA. Mitochondrial DNA phylogeography of host races of the goldenrod ball gallmaker, Eurosta solidaginis (Diptera: Tephritidae). Evolution. 1996;50:777-86.

37. Diegisser T, Johannesen J, Lehr C, Seitz A. Genetic and morphological differentiation in Tephritis bardanae (Diptera: Tephritidae): evidence for host-race formation. J Evol Biol. 2003;17:83-93.

38. Diegisser T, Seitz A, Johannesen J. Phylogeographic patterns of host-race evolution in Tephritis conura (Diptera: Tephritidae). Mol Ecol. 2006;15:681-94

39. Feder JL, Reynolds K, Go W, Wang EC. Intra- and interspecific competition and host race formation in the apple maggot fly, Rhagoletis pomonella (Diptera: Tephritidae). Oecologia. 1995;101:416-25.

40. Djawdan M, Chippindale AK, Rose MR, Bradley TJ. Metabolic reserves and evolved stress resistance in Drosophila melanogaster. Physiol Zool. 1998:71:584-94

41. Hoffmann AA, Parsons PA. An integrated approach to environmental stress tolerance and life-history variation: desiccation tolerance in Drosophila. Biol J Linn Soc. 1989;37:117-36.

42. Kleynhans $E$, Terblanche JS. Complex interactions between temperature and relative humidity on water balance of adult tsetse (Glossinidae: Diptera): implications for climate change. Front Physiol. 2011:2:1-10.

43. Naidu SG. Water balance and osmoregulation in Stenocara gracilipes, a wax-blooming tenebrionid beetle from the Namib Desert. J Insect Physiol. 2001;47:1429-40.

44. Naidu SG, Hattingh J. Water balance and osmoregulation in Physademia globosa, a diurnal tenebrionid beetle from the Namib Desert. J Insect Physiol. 1988;34:911-7.

45. Nicolson SW. Water balance and osmoregulation in Onymacris plana, a tenebrionid beetle from the Namib Desert. J Insect Physiol. 1980;26:315-20.

46. Klok CJ, Chown SL. Critical thermal limits, temperature tolerance and water balance of a sub-antarctic caterpillar, Pringleophaga marioni (Lepidoptera: Tineidae). J Insect Physiol. 1997:43:685-94.

47. Parkash $R$, Aggarwal DD, Kalra B, Ranga P. Divergence of water balance mechanisms in two melanic Drosophila species from the western Himalayas. Comp Biochem Physiol A. 2011;158:531-41.

48. Coenen-Staß D. Investigations on the water balance in the red wood ant Formica polyctena (Hymenoptera, Formicidae): workers, their larvae and pupae. Comp Biochem Physiol. 1986:83A:141-7.

49. Prenter J, Weldon CW, Taylor PW. Age-related activity patterns are moderated by diet in Queensland fruit flies Bactrocera tryoni. Physiol Entomol. 2013;38:260-7. 
50. Hadj Belgacem Y, Martin JR. Neuroendocrine control of a sexually dimorphic behavior by a few neurons of the pars intercerebralis in Drosophila. Proc Natl Acad Sci. 2002;99:15154-8.

51. Baker HG. Characteristics and modes of origin of weeds. In: Baker HG, Stebbins GL, editors. The genetics of colonizing species. New York: Academic; 1965. p. 147-68.

52. Knop E, Reusser N. Jack-of-all-trades: phenotypic plasticity facilitates the invasion of an alien slug species. Proc R Soc B. 2012;279:4668-76.

53. Richards CL, Bossdorf O, Muth NZ, Gurevitch J, Pigliucci M. Jack of all trades, master of some? On the role of phenotypic plasticity in plant invasions. Ecol Lett. 2006:9:981-93.

54. Manrakhan A, Lux SA. Contribution of natural food sources to reproductive behaviour, fecundity and longevity of Ceratitis cosyra, C. fasciventris and C. capitata (Diptera: Tephritidae). Bull Entomol Res. 2006;96:259-68.

55. Warburg MS, Yuval B. Effects of diet and activity on lipid levels of adult Mediterranean fruit flies. Physiol Entomol. 1996;21:151-8.

56. Weldon CW, Terblanche JS, Chown SL. Time-course for attainment and reversal of acclimation to constant temperature in two Ceratitis species. J Therm Biol. 2011;36:479-85.

57. Díaz-Fleischer F, Arredondo J, Aluja M. Enriching early adult environment affects the copulation behaviour of a tephritid fly. J Exp Biol. 2009;212:2120-7.

58. Bradford MM. A rapid and sensitive method for the quantification of microgram quantities of proteins utilizing the principle of protein-dye binding. Anal Biochem. 1976;72:248-54.

59. van Handel E. Microseparation of glycogen, sugars, and lipids. Anal Biochem. 1965:11:266-71.

60. van Handel E. Rapid determination of glycogen and sugars in mosquitoes. J Am Mosq Control Assoc. 1985;1:299-301.

61. van Handel E. Rapid determination of total lipids in mosquitoes. J Am Mosq Control Assoc. 1985;1:302-4.

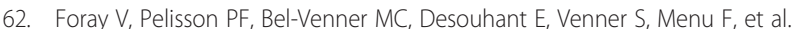
A handbook for uncovering the complete energetic budget in insects: the van Handel's method (1985) revisited. Physiol Entomol. 2012;37:295-302.

63. Yuval B, Kaspi R, Shloush S, Warburg MS. Nutritional reserves regulate male participation in Mediterranean fruit fly leks. Ecol Entomol. 1998;23:211-5.

64. Kaufmann C, Brown MR. Regulation of carbohydrate metabolism and flight performance by a hypertrehalosaemic hormone in the mosquito Anopheles gambiae. J Insect Physiol. 2008;54:367-77.

\section{Submit your next manuscript to BioMed Central and we will help you at every step:}

- We accept pre-submission inquiries

- Our selector tool helps you to find the most relevant journal

- We provide round the clock customer support

- Convenient online submission

- Thorough peer review

- Inclusion in PubMed and all major indexing services

- Maximum visibility for your research

Submit your manuscript at www.biomedcentral.com/submit 